\title{
THERMAL AND ELECTRICAL, ANALYSIS OF MARS ROVER RTG, AND PERFORMANCE COMPARISON OF ALTERNATIVE DESIGN OPTIONS
}

September 29, 1989

A. Schock, T. Or, E. Skrabek

Fairchld Space Company, Germantown, MD 


\section{THERMAL AND ELECTRICAL ANALYSIS OF MARS ROVER RTG, AND PERFORMANCE COMPARISON OF ALTERNATIVE DESIGN OPTIONS}

September 29, 1989

A. Schock, T. Or, E. Skrabek

Fairchld Space Company, Germantown, MD

Fairchild Space Company

Germantown, MD 20874 


\title{
THERMAL AND ELECTRICAL ANALYSIS OF MARS ROVER RTG, AND PERFORMANCE COMPARISON OF ALTERNATIVE DESIGN OPTIONS
}

\author{
A. Schock, T. Or, E. Skrabek \\ Fairchild Space Company, Germantown, MD
}

\begin{abstract}
The paper describes the thermal, thermoelectric and electrical analysis of Radioisotope Thermoelectric Generators (RTGs) for powering the Mars Rover vehicle, which is a critical element of the unmanned Mars Rover and Sample Return mission (MRSR). The work described was part of an RTG design study conducted by Fairchild Space Company for the U.S. Department of Energy, in support of the Jet Propulsion Laboratory's MRSR project.
\end{abstract}

A companion paper presented at this conference described a reference mission scenario, an illustrative Rover design and activity pattern on Mars, its power system requirements and environmental constraints, a design approach enabling RTG operation in the Martian atmosphere, and the design and the structural and mass analysis of a conservative baseline RTG employing safety-qualified heat source modules and reliabilityproven thermoelectric converter elements.

The present paper presents a detailed description of the baseline RTG's thermal, thermoelectric, and electrical analyses. It examines the effect of different operating conditions (beginning versus end of mission, water-cooled versus radiation-cooled, summer day versus winter night) on the RTG's performance. Finally, the paper describes and analyzes a number of alternative RTG designs, to determine the effect of different power levels (250W versus $125 \mathrm{~W}$ ), different thermoelectric element designs (standard versus short unicouples versus multicouples) and different thermoelectric figures of merit $\left(0.00058 \mathrm{~K}^{-1}\right.$ to $\left.0.00140 \mathrm{~K}^{-1}\right)$ on the RTG's specific power.

The results presented show the RTG performance achievable with current technology, and the performance improvements that would be achievable with various technology developments. It provides a basis for selecting the optimum strategy for meeting the Mars Rover design goals with minimal programmatic risk and cost.

\subsection{INTRODUCTION}

A companion paper [1] presented at this conference included a description of a baseline design of a Radioisotope Thermoelectric Generator (RTG) for powering the Martian Rover, a critical element of the unmanned Mars Rover and Sample Return (MRSR) mission under preliminary study by NASA's Jet Propuision Laboratory (JPL). The RTG design study was conducted by the Fairchild Space Company for the U.S. Department of Energy's Office of Special Applications. The RTG design description in the companion paper [1] should be read first, to help understand the work described in the present paper.
The paper describes the coupled thermal, thermoelectric, and electrical analyses of the baseline RTG at the beginning of the mission, with the RTG radiating its waste heat to a $300^{\circ} \mathrm{K}$ Martian environment. The same methodology is then applied to determine the effect of different environmental conditions on the RTG's performance, and to compare the performance of the baseline design with those of various alternative designs of lesser levels of technology readiness. The objective of those comparisons is to quantify the performance improvements achievable if new technologies are successfully developed. When coupled with estimates of the required time, effort, and success probability for those developments, this will help to identify the best strategy for meeting the MRSR system goals.

This paper presents an abbreviated description of the analyses and their results. A much fuller description is contained in a separate Fairchild report [2] available from the author.

The baseline RTG contains a cylindrical array of $\mathbf{5 7 6}$ thermoelectric unicouples, arranged in 36 rings of 16 unicouples. The array surrounds a 38"-long central heat source, consisting of 18 discrete modules. The 576 unicouples are arranged in a $144 \times 4$ series-parallel network, which is designed to produce an output of 30 volts. Because of axial non-uniformities induced by end losses, the 36 converter rings differ appreciably in heat flow rates, temperatures, and efficiencies. Therefore, the analysis must be performed for each separate ring of thermoelectric unicouples.

\subsection{THERMAL AND ELECTRICAL ANALYSIS}

2.1 Need for Coupled Analyses: The thermal, thermoelectric, and electrical analyses of the RTG must be performed simultaneously and interactively. The analysis uses specialized computer codes generated by Fairchild to compute the heat flows, temperatures, and electrical parameters of each layer of thermoelectric elements. Inputs include the RTG design, the thermal input power (BOM/EOM), the cooling mode (water/radiation, Mars-environment), the-TE materials and performance, and the desired electrical output voltage.

The required analysis cannot be carried out by a standard thermal analysis code, because the thermoelectric unicouple is not a simple heat conductor. The heat input rate $\mathbf{Q}_{\mathbf{h}}$ at the couple's hot junction does not equal the heat rejection rate $Q_{c}$ at its cold junction, since part of the input energy is converted into electrical power $P$.

As shown in Figure 1, the heat input rate $\mathrm{Q}_{\boldsymbol{h}}$ consists of four terms: normal heat conduction, Peltier cooling, ohmic heating, and Thomson effect. The heat rejection rate $Q_{c}$ consists of four corresponding terms. All but the first of those 


\subsection{BASELINE RTG RESULTS}

3.1 Temperature Distribution: Figure 3 shows the beginning-of-mission temperature distribution (in ${ }^{\circ} \mathrm{C}$ ) of the radiation-cooled baseline RTG described in the companion paper [1], for a $300^{\circ} \mathrm{K}$ sink temperature. It shows the temperatures of the RTG end regions, and the temperatures at the center of the RTG. The temperatures shown are for an RTG with unicouples of standard dimensions, except that the cross-sectional areas of their SiGe legs have been reduced by $9 \%$ from the corresponding values in the Galileo RTG. This was done in order to take full advantage of the unicouples' maximum temperature capability.

Figure 3. BOM Temperature Distribution $\left({ }^{\circ} \mathrm{C}\right)$ in Baseline RTG
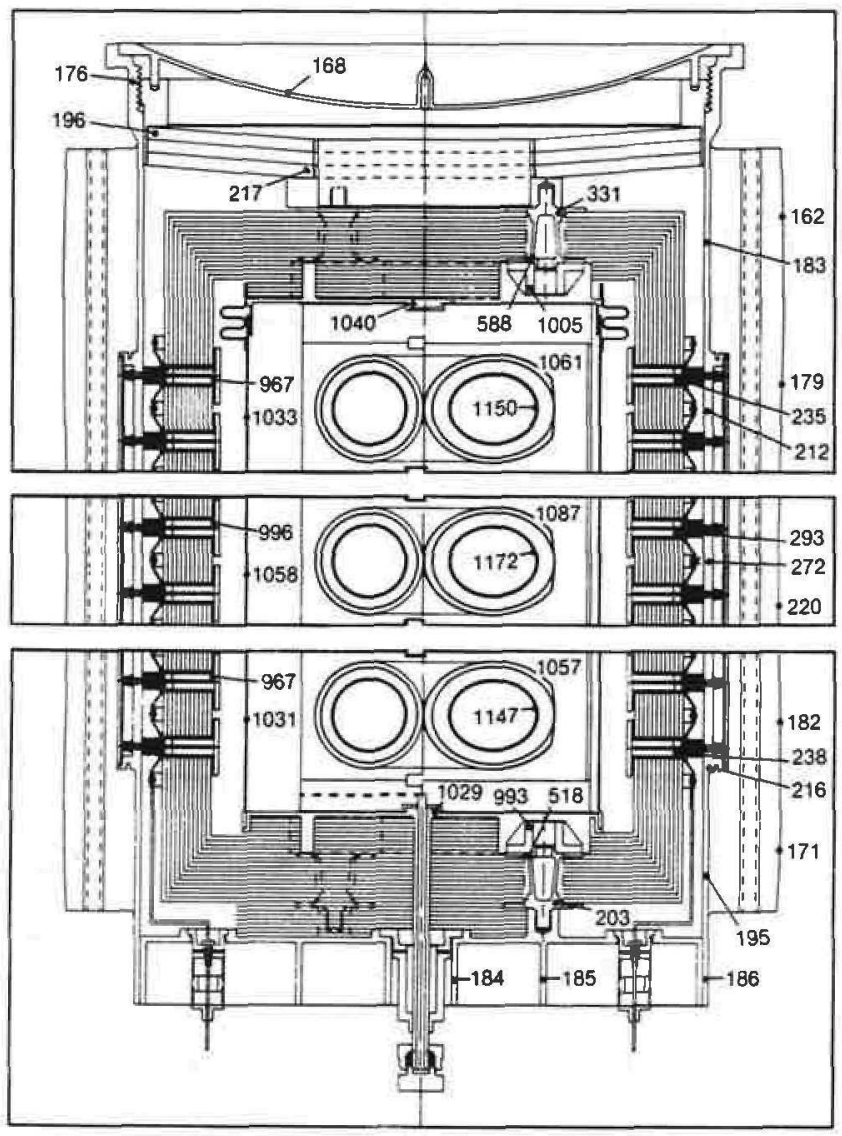

The figure shows the maximum temperatures of the iridium capsules $\left(1172^{\circ} \mathrm{C}\right)$, the graphite heat source surface $\left(1087^{\circ} \mathrm{C}\right)$, the molybdenum canister $\left(1058^{\circ} \mathrm{C}\right)$, the SiGe hot junction $\left(996^{\circ} \mathrm{C}\right)$ and cold junction $\left(293^{\circ} \mathrm{C}\right)$. Of particular interest are the maximum temperatures of the zirconia insulators $\left(1005^{\circ} \mathrm{C}\right)$, the Inconel support studs $\left(588^{\circ} \mathrm{C}\right)$, the titanium springs $\left(217^{\circ} \mathrm{C}\right)$, and the aluminum housing $\left(272^{\circ} \mathrm{C}\right)$, since their mechanical properties and creep characteristics are strong functions of temperature. Note that the maximum hot-junction temperature does not exceed its established $1000^{\circ} \mathrm{C}$ limit, and that the $1172^{\circ} \mathrm{C}$ maximum capsule temperature is far below its established $1330^{\circ} \mathrm{C}$ limit. The reason why the capsule temperature is much lower in the Mars Rover RTG than in the Galileo RTG is the presence of helium inside the canister. Helium greatly reduces the internal temperature drops in the heat source module.
3.2 Axial Temperature Profiles: The axial temperature variations in the RTG are shown in Figure 4. The heat losses from the end of the heat source stack result in the depicted temperature profiles of the fuel capsule clads, the modules' aeroshell surfaces, the canister, and the unicouple hot junctions. The figure also shows the axial temperature variations of the cold junctions, the fin root, and the fin tip.

Figure 4. Axial Temperature Profiles $\left({ }^{\circ} \mathrm{C}\right)$

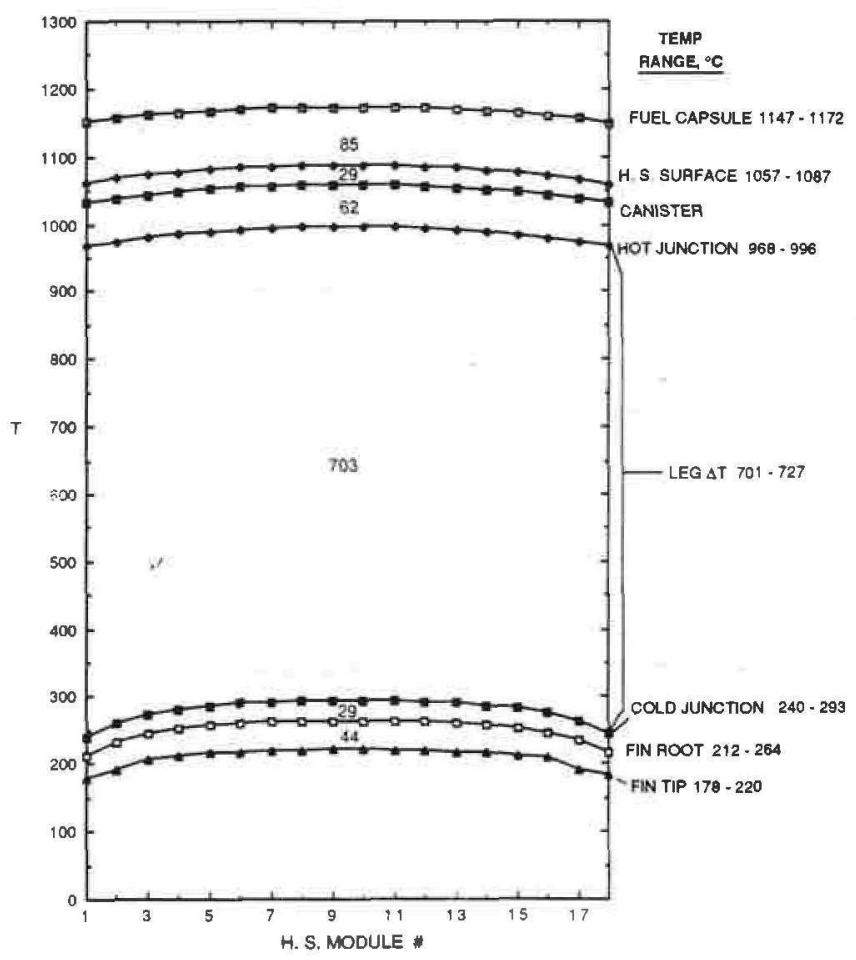

The figure shows six temperature drops between the various curves. The first $\left(-85^{\circ} \mathrm{C}\right)$ represents the drops inside the heat source modules, across the graphitics and helium gaps. The second $\left(29^{\circ} \mathrm{C}\right)$ is the drop across the helium gap to the canister, and the third $\left(-62^{\circ} \mathrm{C}\right)$ is across the vacuum gaps and through the TE heat collectors. The fourth $\left(703^{\circ} \mathrm{C}\right)$ is the temperature drop across the SiGe TE legs. As can be seen, this is the largest of the drops. It is the only one that makes a useful contribution in actually generating electrical power. All the other temperature drops represent thermodynamic losses. The fifth drop $\left(\sim 29^{\circ} \mathrm{C}\right)$ represents the thermal resistance of the unicouple's cold-end and the loss for circumferential heat transport through the aluminum housing to the nearest fin; and the sixth drop $\left(44^{\circ} \mathrm{C}\right)$ is that due to radial heat flow through the fin itself.

The depicted variation of the hot-junction temperatures would result in a significant performance loss, were it not balanced by a similar convex profile of the cold-junction temperatures. This was achieved by extending the radiator fins beyond the active length of the RTG, as mentioned earlier. In fact, the temperature drop-off of the cold junctions near the RTG ends is greater than that of the hot junctions. This explains why the unicouples' heat flow rates, power outputs, and efficiencies are actually higher at the ends of the RTG than at the center, as shown in Figures 5 and 6. 


\subsection{SIMPLIFIED RTG ANALYSIS}

In addition to the detailed thermal, thermoelectric, and electrical analyses described above, a simplified analysis was used for scoping studies and to assess the effect of thermoelectric properties on RTG performance. The simplified analysis ignored the axial variation of temperatures, heat flow rates, and efficiencies. Instead of analyzing discrete layers of thermoelectric couples, it assumed that all couples in the RTG operate at the same hot- and cold-junction temperatures $\left(1000^{\circ} \mathrm{C}, 300^{\circ} \mathrm{C}\right)$. The simplified analysis includes an optimization of the leg area ratio and of the couple voltage, and the determination of the number of heat source modules and thermoelectric couple layers and of the couples' length-toarea ratio to match the prescribed output power and voltage of the RTG. The derived equations take account of the temperature dependence of the couple's Seebeck coefficient and of the resultant Thomson effect.

4.1 Thermoelectric Couple Analysis: From Figure 1, the couple's conversion efficiency $\eta$ is given by

$$
\eta=\frac{I V}{Q_{h}}=\frac{I V}{K \Delta T+I S_{h} T_{h}-I^{2} R / 2-I\left(S_{h} T_{h}-S_{c} T_{c}-S \Delta T\right) / 2}
$$

and its current I is related to its output voltage $\mathrm{V}$ by the voltage balance

$$
S \Delta T=I R+V
$$

Solving Eq. (2) for I and inserting the results into (1), we obtain

$$
\eta=\frac{V(S \Delta T-V)}{K R \Delta T+\left(S_{h} T_{h}+S_{c} T_{c}+S \Delta T\right)(S \Delta T-V) / 2-(S \Delta T-V)^{2} / 2}
$$

which is the general solution for the efficiency of a thermoelectric couple, before optimization of its output voltage $\mathrm{V}$ and of the ratio of its $\mathrm{n}$ - and p-leg aréas. From Figure 1, the couple's thermal conductance $\mathbf{K}$ and electrical resistance $\mathbf{R}$ are given by

$K=\left[k_{n} \alpha+k_{p}(1-\alpha)\right](A / L)$

$R=\left[\rho_{n} / \alpha+\rho_{p} /(1-\alpha)\right](L / A)$

where $\alpha$ is the area fraction of the $n$-leg and 1- $\propto$ is the area fraction of the $p$-leg, and $A$ is the combined area of the two legs. Combining these, the product $\mathbf{K R}$ is given by

$$
K R=k_{n} \rho_{n}+k_{p} \rho_{p}+k_{n} \rho_{p}\left\lfloor\frac{\alpha}{1-\alpha}\right\rfloor+k_{p} \rho_{n}\left\lfloor\frac{1-\alpha}{\alpha}\right\rfloor
$$

Note that for a given set of hot- and cold-junction temperatures the product $\mathbf{K R}$, and therefore the efficiency $\boldsymbol{\eta}$, are independent of the leg dimensions $\mathbf{L}$ and $\mathbf{A}$. The value of $\alpha$ which minimizes the product $\mathbf{K R}$ and therefore maximizes the efficiency $n$ is given by

$\alpha_{o p t}=\left[1+\sqrt{\left(k_{n} / k_{p}\right)\left(\rho_{p} / \rho_{n}\right)}\right]^{-1}$

Inserting this into Eq. (6), we obtain the minimum value of the product $\mathbf{K R}$,

$(K R)_{\min }=\left[\sqrt{k_{n} \rho_{n}}+\sqrt{k_{p} \rho_{p}}\right]^{2}$

Inserting Eq. (8) into (3) gives the efficiency $n$ ' of a couple with optimized leg area fraction,

$\eta^{\prime}=\frac{(S \Delta T / V-1)^{-1}}{\left[\frac{\sqrt{k_{n} \rho_{n}}+\sqrt{k_{p} \rho_{p}}}{S \Delta T-V}\right]^{2} \Delta T+\frac{S_{h} T_{h}+S_{c} T_{c}+S \Delta T}{2(S \Delta T-V)}-\frac{1}{2}}$
The preceding expression is maximized by setting the couple output voltage equal to

$V_{o p t}=S \Delta T\left[1+\frac{1}{\sqrt{(1+Z \bar{T})}}\right]^{-1}$

where $\mathbf{Z}$ is the thermoelectric materials' temperature-ave: sed figure of merit, defined by

$Z \equiv S^{2} /\left[\sqrt{k_{n}} \rho_{n}+\sqrt{k_{p}} \rho_{p}\right]^{2}$

and $\overline{\mathbf{T}}$ is an average temperature defined by

$\bar{T}=\left(S_{h} T_{h}+S_{c} T_{c}\right) / 2 S$

Inserting Eq. (10) into (9) gives the maximum efficiency a couple with optimized leg area fraction $\alpha$ and optimizis

$\eta^{\prime \prime}=\frac{\sqrt{(1+Z \bar{T})}}{\frac{(\sqrt{(1+Z \bar{T})}+1)^{2}}{Z \bar{T}}\left(\frac{\bar{T}}{\Delta T}\right)+\left(\frac{1}{2}+\frac{\bar{T}}{\Delta T}\right)(\sqrt{(1+Z \bar{T})}+1)-\frac{1}{2}}$

Eqs. (12) and (13) differ from previously published [3] forms because they include the effect of the Thomson coefficient. Note that in the special case when the temperature dependence of the Seebeck coefficient is negligible (i.e., $S_{h}=S_{c}=S$ ), the average temperature $\overline{\mathbf{T}}$ from Eq. (12) reduces to the arithmetic mean temperature. Then, since the Carnot efficiency is given by

$\eta_{c} \equiv \Delta T / T_{h}=[\bar{T} / \Delta T+1 / 2]^{-1}$

the maximum efficiency $\eta^{\prime \prime}$ for that special case reduces to

$$
\eta^{\prime \prime}=\eta_{c}\left[1+\frac{2-\eta_{c}}{\sqrt{(1+Z \bar{T})}-1}\right]^{-1}
$$

For the general case of temperature-dependent Seebeck coefficient and non-zero Thomson coefficient, Eqs. (10) through (13) show that the optimum couple voltage and maximum efficiency are functions of only the thermoelectric material properties and the operating temperatures. Figure 7 presents a semi-log plot of the voltage ratio $\mathrm{V}_{\text {opt }} / \mathbf{S} \Delta \mathbf{T}$ as a function of $\overline{Z T}$, and Figure 8 presents a semi-log plot of $\eta^{\prime \prime}$ versus $\overline{Z T}$ for various values of $\bar{T} / \Delta T$. Figure 7 shows that the matched-load condition ( $\mathrm{V}=0.5 \mathrm{~S} \Delta \mathrm{T}$ ) does not yield the maximum efficiency. The greater the value of $\overline{Z T}$, the more the optimum deviates from matched load.

Figure 7. Effect of Figure of Merit $Z$ and Temperature $\bar{T}$ on Optimum Load Voltage Vopt

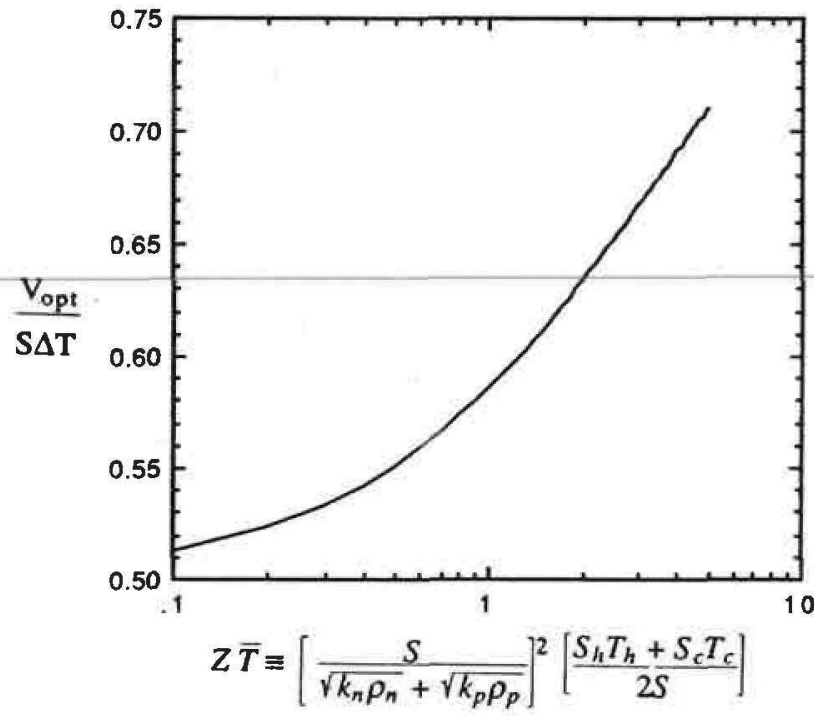


the housing. As will be seen, these differences affect the Rover RTG design.

Figure 9. Multicouple Cross-Section

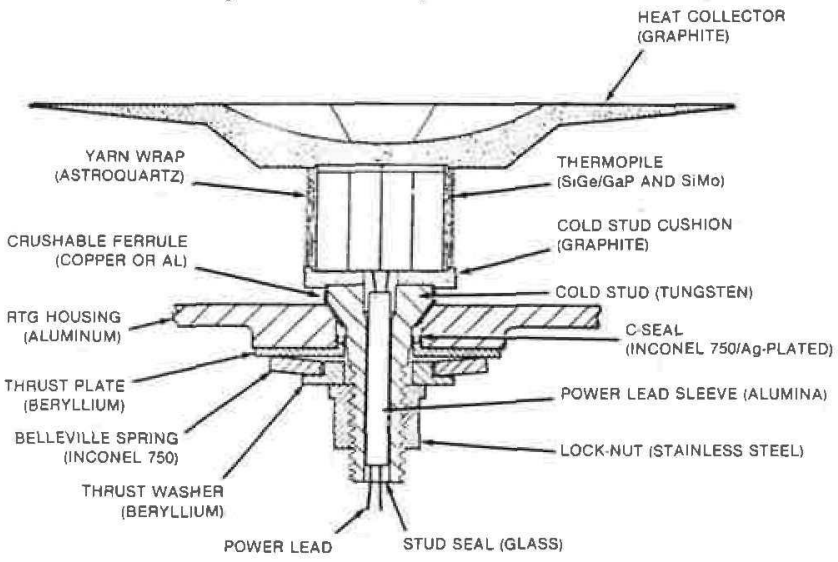

Multicouples operating at the required hot-junction temperature $\left(1000^{\circ} \mathrm{C}\right)$ have a much smaller data base than unicouples, which have successfully operated for periods in excess of 100,000 hours. Multicouple development was initiated in the late 1970s [4], their present design was defined in 1983 [5], and their most successful test to date (of an assembly of eight multicouples produced at GE and tested at Fairchild) ran for 6000 hours, until it was interrupted for a planned modification of the test fixture and for withdrawal of some of the multicouples for destructive examination in late 1988. The test results indicated that multicouples can deliver stable performance with only modest degradation, at least for 6000 hours.

5.2 Multicouple RTG Design: A horizontal crosssection of an RTG employing standard-size multicouples is shown in Figure 10. The multicouple-RTG design is generally similar to the unicouple-RTG design shown in Reference [1], and only the significant differences will be mentioned.

As in the MITG and Mod-RTG designs [4,5], there are eight multicouples per horizontal layer, and only one multicouple layer per heat source module. For a 250-watt(e) power output, the RTG has 16 heat source modules. Thus, there are 128 multicouples per RTG, or about one fifth as many thermoelectric units as in the baseline unicouple RTG

In the Mod-RTG the multicouple mounting holes are sealed by conical metal ferrules, but these would be inadequate for preventing inflow of the Martian atmosphere during longterm operations on Mars. Therefore, the bolt holes in the present design are hermetically sealed by eight semi-cylindrical aluminum seal covers welded to the aluminum housing hubs.

In the standard multicouple design, the leads pass through the housing wall, and are series-connected on the outside. To preserve hermeticity in the present RTG design, the series leads are passed back to the inside of the housing via insulated studs, for internal series connections between the eight multicouples in each ring.

As in the Mod-RTG, the eight multicouples are embedded in a $0.3^{\prime \prime}$-thick layer of thermal insulation, consisting of 60 layers of 0.00 : "thick molybdenum foils, separated from each other by zircona spacer particles. This type of insulation is not only lighter than the standard unicouple insulation, but its lower thickness also leads to significant weight saving due to the consequent reduction in housing diameter from $9^{\prime \prime}$ to $7.5^{\prime \prime}$.

Figure 10. Multicouple RTG, Horizontal Cross-Section

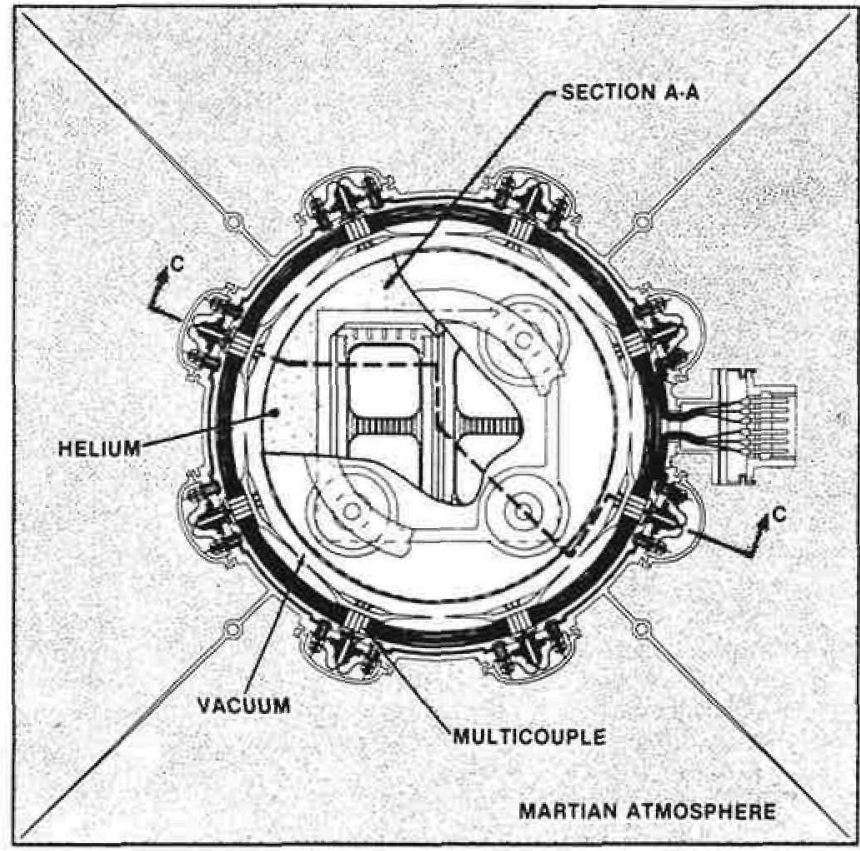

The option shown in Figure 10 has four radiator fins. The alternative of eight (shorter and thinner) fins was also analyzed. The analytical results showed that the two options yield very similar specific powers.

As shown, the series connections between the multicouples are horizontal rather than vertical. The multicouple RTG design is modular [4], because each horizontal ring produces the desired RTG voltage (30V). The 16 rings are connected in parallel. To isolate the effect of possible shorts-to-ground, the leads from each of the sixteen current loops are separately brought out to the power conditioning unit through a multipin terminal near the base of the RTG, as shown at the right of Figure 10.

5.3 Short-Unicouple RTG: As shown in Section 6, the multicouple RTG has a substantially higher specific power than the baseline unicouple RTG. But since the long-term performance stability of multicouples has not yet been adequately demonstrated and may not be achievable in time for the projected MRSR mission schedule, the possibility of achieving a significant part of the performance improvement of the multicouple RTG in a modified unicouple RTG of considerable interest. This may be achievable by developing short-legged unicouple with GaP-doped n-legs.

The design of the short-unicouple RTG is in most respects similar to the previously described baseline RTG, and only the significant differences will be listed:

- The unicouples have a leg length of 0.4 " instead of $0.8^{\prime \prime}$.

- Their heat collectors are 1.50" x 1.46" instead of $1.06 "$ $x 0.90^{\prime \prime}$. 
Table 1: RTG Design and Perlormance Parameters

\begin{tabular}{|c|c|c|c|c|c|c|c|c|c|c|}
\hline $\begin{array}{l}\text { RTG } \\
\text { Type } \\
\end{array}$ & \multicolumn{4}{|c|}{$\begin{array}{l}\text { Basellne : } \\
\text { RTG }\end{array}$} & \multicolumn{2}{|c|}{$\begin{array}{r}\text { Short } \\
\text { RTG }\end{array}$} & $\begin{array}{c}\text { Doped } \\
\text { RTG }\end{array}$ & $\begin{array}{c}\text { Short UC } \\
\text { RTG }\end{array}$ & \multicolumn{2}{|c|}{$\begin{array}{l}\text { MC } \\
\text { RTG }\end{array}$} \\
\hline $\begin{array}{l}\text { TE Element } \\
\text { P-Leg Material } \\
\text { N-Leg Material } \\
\text { Leg Length, in } \\
\text { Couples per TE Element } \\
\text { Leg Area, sq. in. } \\
\text { TE Couple Figure of Merit, } 0.001 / \mathrm{K}\end{array}$ & & $\begin{array}{c}\text { UC } \\
\text { SiG } \\
\text { SiG } \\
0.8 \\
1 \\
0.052 \\
0.58\end{array}$ & & & $\begin{array}{r}\mathrm{UC} \\
\mathrm{SiC} \\
\mathrm{SiC} \\
0 . \\
1 \\
0.04 \\
0.5\end{array}$ & & $\begin{array}{c}\mathrm{UC} \\
\mathrm{SiGe} \\
\mathrm{SiGe} / \mathrm{GaP} \\
0.8 \\
1 \\
0.0645 \\
0.72\end{array}$ & $\begin{array}{c}\mathrm{UC} \\
\mathrm{SiGe} \\
\mathrm{SiGe} / \mathrm{GaP} \\
0.4 \\
1 \\
0.0627 \\
0.72\end{array}$ & $\begin{array}{r}\text { MC } \\
\text { SiGe } \\
\text { SiGe/G } \\
0.3 \\
20 \\
0.097 \\
0.72\end{array}$ & \\
\hline $\begin{array}{l}\text { Number of H. S. Modules per RTG } \\
\text { Number of TE Rings per RTG } \\
\text { Number of TE Elements per Ring } \\
\text { Number of TE Elements per RTG } \\
\text { Number in Parallel } \\
\text { Number in Series }\end{array}$ & & $\begin{array}{c}18 \\
36 \\
16 \\
576 \\
4 \\
144\end{array}$ & & & $\begin{array}{r}9 \\
18 \\
16 \\
28 \\
2 \\
14\end{array}$ & & $\begin{array}{c}18 \\
36 \\
16 \\
576 \\
4 \\
144\end{array}$ & $\begin{array}{c}18 \\
26 \\
12 \\
312 \\
2 \\
156\end{array}$ & $\begin{array}{c}16 \\
16 \\
8 \\
128 \\
16 \\
8\end{array}$ & \\
\hline $\begin{array}{l}\text { RTG Length, in } \\
\text { RTG Housing Diameter, in } \\
\text { RTG Housing Thickness, in }\end{array}$ & \multicolumn{4}{|c|}{$\begin{array}{c}45.9 \\
9.1 \\
0.09\end{array}$} & \multicolumn{2}{|c|}{$\begin{array}{c}26.7 \\
9.1 \\
0.06\end{array}$} & $\begin{array}{c}45.9 \\
9.1 \\
0.09\end{array}$ & $\begin{array}{c}45.9 \\
9.1 \\
0.09\end{array}$ & \multicolumn{2}{|c|}{$\begin{array}{c}41.6 \\
7.5 \\
0.0625\end{array}$} \\
\hline $\begin{array}{l}\text { Number of Fins } \\
\text { Fin Root Thickness, in } \\
\text { Fin Length, in }\end{array}$ & \multicolumn{4}{|c|}{$\begin{array}{c}8 \\
0.06 \\
3\end{array}$} & \multicolumn{2}{|c|}{$\begin{array}{c}8 \\
0.06 \\
3\end{array}$} & $\begin{array}{c}8 \\
0.06 \\
3\end{array}$ & $\begin{array}{c}6 \\
0.08 \\
4\end{array}$ & \multicolumn{2}{|c|}{$\begin{array}{c}4 \\
0.10 \\
5.5\end{array}$} \\
\hline $\begin{array}{l}\text { Mass Breakdown, kg } \\
\text { GPHS Modules } \\
\text { H. S. Canister } \\
\text { H. S. Structural Support } \\
\text { Electrical Circuits } \\
\text { Multifoil Insulation } \\
\text { RTG Housing } \\
\text { Radiator } \\
\text { Total Mass per RTG }\end{array}$ & \multicolumn{4}{|c|}{$\begin{array}{r}26.05 \\
3.77 \\
3.94 \\
7.74 \\
5.94 \\
8.45 \\
2.78 \\
58.67\end{array}$} & \multicolumn{2}{|c|}{$\begin{array}{r}13.03 \\
2.38 \\
2.18 \\
3.96 \\
3.31 \\
4.52 \\
1.78 \\
31.15\end{array}$} & $\begin{array}{r}26.05 \\
3.77 \\
3.94 \\
7.74 \\
5.94 \\
8.45 \\
2.78 \\
58.67\end{array}$ & $\begin{array}{r}26.05 \\
3.77 \\
3.94 \\
5.98 \\
3.11 \\
7.44 \\
2.78 \\
53.07\end{array}$ & $\begin{array}{r}23.16 \\
3.52 \\
2.59 \\
2.84 \\
4.03 \\
6.78 \\
2.33 \\
45.25\end{array}$ & \\
\hline $\begin{array}{l}\text { Mission Time, BOM/EOM } \\
\text { Thermal Power, W } \\
\text { Cooling Mode, Convective/Radiative } \\
\text { Martian Ground Temperature, K }\end{array}$ & $\begin{array}{c}\text { BOM } \\
4396 \\
\text { C } \\
-\end{array}$ & $\begin{array}{l}\text { BOM } \\
4396 \\
\mathrm{R} \\
140\end{array}$ & $\begin{array}{c}\text { BOM } \\
4396 \\
\text { R } \\
300\end{array}$ & $\begin{array}{c}\text { EOM } \\
4261 \\
R \\
300\end{array}$ & $\begin{array}{c}\text { BOM } \\
2198 \\
\text { R } \\
300\end{array}$ & $\begin{array}{c}\text { EOM } \\
2131 \\
\text { R } \\
300\end{array}$ & $\begin{array}{c}\text { BOM } \\
4396 \\
\text { R } \\
300\end{array}$ & $\begin{array}{l}\text { BOM } \\
4396 \\
\text { R } \\
300\end{array}$ & $\begin{array}{c}\text { BOM } \\
3907 \\
\text { R } \\
300\end{array}$ & $\begin{array}{c}\text { FOM } \\
3787 \\
\text { R } \\
300\end{array}$ \\
\hline $\begin{array}{l}\text { Maximum Temperature, }{ }^{\circ} \mathrm{C} \\
\text { Fuel Clad } \\
\text { H. S. Surface } \\
\text { Canister } \\
\text { TE Hot Junction } \\
\text { TE Cold Junction } \\
\text { Fin Root } \\
\text { Fin Tip }\end{array}$ & $\begin{array}{r}1091 \\
994 \\
959 \\
890 \\
156 \\
116 \\
101\end{array}$ & $\begin{array}{r}1168 \\
1082 \\
1054 \\
991 \\
281 \\
252 \\
214\end{array}$ & $\begin{array}{r}1175 \\
1090 \\
1061 \\
999 \\
291 \\
261 \\
224\end{array}$ & $\begin{array}{r}1159 \\
1073 \\
1045 \\
984 \\
287 \\
258 \\
221\end{array}$ & $\begin{array}{r}1174 \\
1088 \\
1060 \\
1000 \\
278 \\
246 \\
210\end{array}$ & $\begin{array}{r}1157 \\
1071 \\
1043 \\
985 \\
274 \\
242 \\
208\end{array}$ & $\begin{array}{r}1173 \\
1088 \\
1059 \\
997 \\
290 \\
260 \\
223\end{array}$ & $\begin{array}{r}1196 \\
1114 \\
1087 \\
996 \\
312 \\
257 \\
210\end{array}$ & $\begin{array}{r}1159 \\
1071 \\
1041 \\
992 \\
316 \\
259 \\
184\end{array}$ & $\begin{array}{r}1141 \\
1053 \\
1024 \\
974 \\
311 \\
256 \\
182\end{array}$ \\
\hline $\begin{array}{c}\text { Efficiency, \% } \\
\text { Material } \\
\text { Couple } \\
\text { Converter } \\
\text { System }\end{array}$ & $\begin{array}{l}8.05 \\
7.72 \\
6.67 \\
6.57\end{array}$ & $\begin{array}{l}7.93 \\
7.72 \\
6.62 \\
6.48\end{array}$ & $\begin{array}{l}7.91 \\
7.70 \\
6.60 \\
6.44\end{array}$ & $\begin{array}{l}7.43 \\
7.23 \\
6.22 \\
6.08\end{array}$ & $\begin{array}{l}8.13 \\
7.92 \\
6.75 \\
6.42\end{array}$ & $\begin{array}{l}7.64 \\
7.43 \\
6.36 \\
6.05\end{array}$ & $\begin{array}{l}8.72 \\
8.28 \\
7.04 \\
6.89\end{array}$ & $\begin{array}{l}8.47 \\
7.89 \\
6.69 \\
6.55\end{array}$ & $\begin{array}{l}8.41 \\
8.02 \\
7.15 \\
6.86\end{array}$ & $\begin{array}{l}7.96 \\
7.59 \\
6.76 \\
6.50\end{array}$ \\
\hline $\begin{array}{l}\text { RTG Output } \\
\text { Current, A } \\
\text { Voltage, V } \\
\text { Power, W }\end{array}$ & $\begin{array}{r}9.63 \\
30.0 \\
289\end{array}$ & $\begin{array}{r}9.49 \\
30.0 \\
285\end{array}$ & $\begin{array}{r}9.43 \\
30.0 \\
283\end{array}$ & $\begin{array}{l}8.64 \\
30.0 \\
259\end{array}$ & $\begin{array}{r}4.71 \\
30.0 \\
141\end{array}$ & $\begin{array}{r}4.30 \\
30.0 \\
129\end{array}$ & $\begin{array}{r}10.09 \\
30.0 \\
303\end{array}$ & $\begin{array}{r}9.60 \\
30.0 \\
288\end{array}$ & $\begin{array}{r}9.10 \\
29.5 \\
268\end{array}$ & $\begin{array}{r}8.34 \\
29.5 \\
246\end{array}$ \\
\hline Specific Power, W/kg & 4.93 & 4.86 & 4.82 & 4.41 & 4.53 & 4.14 & 5.16 & 5.42 & 5.92 & 5.44 \\
\hline
\end{tabular}


